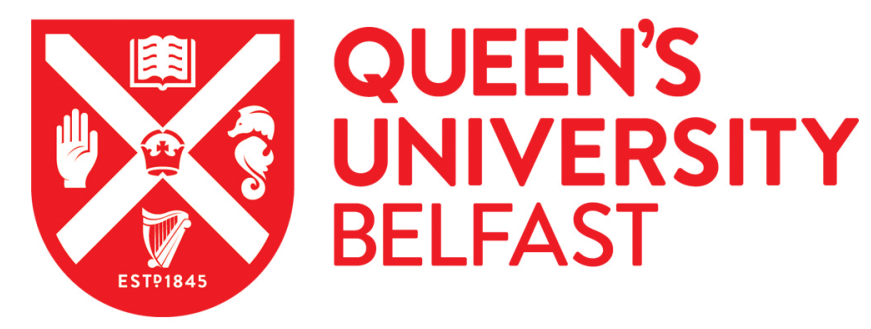

\title{
Neighborhood signaling effects, commuting time, and employment: Evidence from a field experiment
}

Carlsson, M., Reshid, A. A., \& Rooth, D-O. (2018). Neighborhood signaling effects, commuting time, and employment: Evidence from a field experiment. International Journal of Manpower. https://doi.org/10.1108/IJM09-2017-0234

Published in:

International Journal of Manpower

Document Version:

Peer reviewed version

Queen's University Belfast - Research Portal:

Link to publication record in Queen's University Belfast Research Portal

Publisher rights

(C) 2017 Emerald Publishing Limited.

This work is made available online in accordance with the publisher's policies. Please refer to any applicable terms of use of the publisher.

\section{General rights}

Copyright for the publications made accessible via the Queen's University Belfast Research Portal is retained by the author(s) and / or other copyright owners and it is a condition of accessing these publications that users recognise and abide by the legal requirements associated with these rights.

Take down policy

The Research Portal is Queen's institutional repository that provides access to Queen's research output. Every effort has been made to ensure that content in the Research Portal does not infringe any person's rights, or applicable UK laws. If you discover content in the Research Portal that you believe breaches copyright or violates any law, please contact openaccess@qub.ac.uk. 


\section{Introduction}

In many major metropolitan cities, there are neighborhoods that consist of clusters of individuals with low incomes and high levels of unemployment (see, e.g., Durlauf, 2004, and Aldén and Hammarstedt, 2016). These neighborhoods are usually further characterized by low education levels, high concentrations of residents with foreign backgrounds, and high crime rates (Andersson and Bråmå, 2004; Andersson et al., 2010; Grönqvist et al., 2015; Tammaru et al., 2015). An important and policy relevant question is whether living in such neighborhoods causes poor individual labor market outcomes, and if so, what the mechanisms are. By conducting a field experiment in which residential addresses for different types of neighborhoods are randomly attached to fictitious job applications, we set out to improve the answer to this question.

Empirically estimating causal neighborhood effects has proven to be difficult. Since residential location is an endogenous choice, there could be negative selection of individuals with lower skills into deprived neighborhoods. In this case, there is no real neighborhood effect, and instead, observed differences are driven by unobserved individual productivity differences.

A number of potential mechanisms could explain a causal neighborhood effect, and distinguishing among them is an empirical challenge. A first mechanism relates to the labor demand side, where employers assume that individual productivity is lower among job candidates living in deprived neighborhoods. As a result, employers may statistically discriminate (Phelps, 1972; Arrow, 1973) against them. In theories based on statistical discrimination, it is assumed that information about individual productive attributes is incomplete, and employers therefore use easily observable group characteristics to predict unobserved individual productivity. In our case, statistical discrimination implies that employers assume that individual productivity is lower for workers living in deprived neighborhoods. Thus, there could be a negative neighborhood signaling effect (Wacquant, 1993; Atkinson and Kintrea, 2001). A second set of pathways, but 
now on the supply side, is related to the amount of social capital available in a neighborhood. For example, worse economic outcomes of deprived neighborhoods could result from a lack of good role models, negative peer influences and weak labor market networks (Wilson, 1987; Borjas, 1995). A third possible mechanism, often referred to as the spatial mismatch effect, is that deprived neighborhoods may be located further away from available jobs, which could create a barrier to accessing jobs. ${ }^{1}$ On the supply side, a longer distance to the job could lead to lower search intensity due to higher transportation costs, less access to information about job openings and, therefore, higher search costs. On the demand side, employers could statistically discriminate against workers who commute long distances (see also Gobillon et al., 2007). The reason could be that employers view job candidates with long commutes as less productive if commuting makes a worker inflexible, takes considerable energy, and increases absences from work.

The main contribution of this study is to improve our understanding of the role of neighborhood signaling effects for employment opportunities. While such signaling effects are emphasized in the theoretical literature, few empirical studies try to estimate neighborhood signaling effects. A first study related to ours is the Moving to Opportunity experiment (Katz et al., 2001), which addresses the potential problem with selection bias in observational studies ${ }^{2}$ by conducting a lottery in which some families living in deprived neighborhoods in five US cities (Baltimore, Boston, Chicago, Los Angeles and New York) were randomly given the opportunity to move to a better neighborhood located nearby. This study finds no short-run effects on employment of moving to a better neighborhood. However, in a follow-up study of the long-term

\footnotetext{
${ }^{1}$ See Ihlanfeldt and Sjoquist (1998) for a review of the empirical literature on the spatial mismatch hypothesis.

${ }^{2}$ Most studies use observational data to study neighborhood effects. For example, Atkinson and Kinterea (2001) use survey data to study neighborhood effects and Galster et al. (2015) use longitudinal data to study neighborhood effects in Sweden. See Durlauf (2004) for an overview of the literature on neighborhood effects.
} 
effects, Chetty et al. (2016) find that adults who moved to a better neighborhood at a young age (below age 13) are more likely to have attended college, have higher income and less likely to be a single parent. Although experiments of this type make the neighborhood exogenous, they do not necessarily help distinguish between neighborhood signaling effects and other potential mechanisms beyond selection.

The study by Bertrand and Mullainathan (2004) takes a step in the direction of revealing causal pathways. Although the study was primarily designed to measure ethnic discrimination, their field experiment is also relevant for investigating neighborhood signaling effects. They randomly assigned fictitious job applications black or white names and applied for real jobs, ruling out both the selection of individuals into neighborhoods and any mechanism working through social capital. They find that job applicants signaling living in more affluent neighborhoods in terms of the fraction of white residents, the level of education and the level of income have higher callback rates for job interviews, and that this neighborhood signaling effect is the same for both whites and blacks. However, they do not control for employers potentially using the distance to work as a sorting factor, that is, for potential systematic correlations between the type of neighborhood and the distance to the job.

We are only aware of two studies that set out to specifically identify neighborhood signaling effects. Both are field experiments with a similar design as in Bertrand and Mullainathan (2004). Tunstall et al. (2014) randomly assign neighborhoods with similar distances to the job, thereby controlling for distance to work by design, while Phillips (2016) randomly and independently assign neighborhood and distance to the job, which enables him to identify neighborhood signaling effects.

However, these two studies do not consider heterogeneity in neighborhood signaling effects, such as whether they vary by the ethnic background of the job applicant. Heterogeneity by 
ethnicity may be important if there is statistical ethnic discrimination (e.g., Phelps, 1972, Arrow, 1973, Aigner and Cain, 1977) in hiring. In this case, the type of neighborhood may constitute a stronger signal of productivity for minority job applicants than for majority applicants. For ethnic minority applicants employers may, e.g., consider the type of neighborhood as a good predictor of soft skills, such as host-country specific social capital and communication skills, while the signal may contain little information about the productivity of majority applicants. ${ }^{3}$ This highlights that an estimate of the average neighborhood signaling effect may hide information that could be important for policy makers.

This study contributes to the literature in a number of ways. First, it adds to the small literature that identifies neighborhood signaling effects on hiring. Second, we consider heterogeneity in neighborhood signaling effects by ethnic background. Finally, our study provides evidence on whether employers consider commuting distance when deciding which applicant to hire.

To investigate neighborhood signaling effects, we conducted a field experiment where 2,790 job applications were sent to employers with a job vacancy. The measured outcome was callbacks from employers for job interviews. Postal addresses in typically affluent and deprived neighborhoods in the Stockholm and Gothenburg labor market areas were randomly assigned to otherwise qualitatively similar job applications. Randomizing neighborhood type and controlling for commuting time allow us to identify the causal neighborhood signaling effect. In addition to the type of neighborhood, we randomly assigned ethnicity and gender signals (through the applicant's name). This type of experiment has mostly been used to study ethnic, gender, and age

\footnotetext{
${ }^{3}$ Bartoš et al. (2016) propose a different model of "attention discrimination" that also can explain heterogeneity w.r.t ethnicity. This model predicts that in a labor market with a high callback rate, employers have a higher net benefit from engaging in costly information gathering for ethnic minority job applicants, for example about the type of neighborhood the applicant lives in. The reason is that there is a higher chance that the information will change the decision for these job applicants. In contrast, most majority job applicants are assumed to be qualified anyway so in this case it is not optimal to engage in costly information gathering.
} 
discrimination (see, e.g., Riach and Rich, 2002, Bertrand and Mullainathan, 2004, Neumark et al., 1996, and Lahey, 2008) ${ }^{4}$ and unemployment scarring effects (Eriksson and Rooth, 2014; Kroft et al.s, 2013).

\section{Experimental design}

We conducted a field experiment where job applications were sent to employers with a job vacancy, which enable us to identify the causal effects of variables that are randomly assigned to the job applications. The key variable that is randomly assigned in our experiment is the neighborhood the job applicant resides in, which is signaled by the postal address stated in the resume. The measured outcome is callbacks from employers in the form of invitations to job interviews.

This field experiment is part of a larger research project that has an objective of testing for labor market discrimination on the basis of ethnicity, gender, and history of unemployment, as well as other hypotheses (Eriksson and Rooth, 2014; Carlsson et al., 2015). Except for ethnicity these dimensions are not analyzed in this paper.

\subsection{Selecting neighborhoods}

We focus on two major cities in Sweden - Stockholm and Gothenburg. The majority of advertised jobs are found here, and it is only in the larger cities where there is considerable variation in neighborhood type. The relatively wealthy and those with Swedish backgrounds ${ }^{5}$ tend to live in affluent neighborhoods in the central parts of these cities, while the relatively poor

\footnotetext{
${ }^{4}$ Other studies are Carlsson and Rooth (2007), Carlsson (2010), Carlsson (2011), Rich (2014), Baert et al. (2015), Riach (2015), Baert et al. (2016a and 2016b), Lee and Khalid (2016), Midtbøen (2016), Neumark (2016), Baert (2017), Carlsson and Eriksson (2017), and Weichselbaumer (2017).

${ }^{5}$ We define a Swedish background as being born in Sweden and having two Swedish born parents. Other individuals are defined as having a foreign background.
} 
and those with foreign backgrounds tend to live in deprived neighborhoods outside the central parts. People living in the relatively poor neighborhoods have lower employment rates and incomes (Andersson and Bråmå, 2004; Alden and Hammarstedt, 2016).

We study neighborhood signaling effects at the SAMS (Small Areas for Market Statistics) level. Statistics Sweden divides Sweden into approximately 9,000 small areas that are intended to be homogenous neighborhoods w.r.t socioeconomic characteristics. SAMS have an average population of approximately 1,000 residents. This division facilitates the study of neighborhood effects.

In the experiment, we include two categories of clearly distinct SAMS. Areas in each category were selected to be representative of a typical affluent (henceforth, good) or deprived (henceforth, bad) SAMS. We choose SAMS based on a geographic index of economic segregation (National Board of Health and Welfare, 2006). ${ }^{6}$ For both cities, we selected the three most affluent and the three most deprived SAMS. For each SAMS, we then chose a postal address to be used in the experiment with a housing type that is typical for the SAMS. ${ }^{7}{ }^{8}$ In the end, we selected twelve different addresses ( 2 cities x 2 types of neighborhood x 3 addresses per type of neighborhood).

Since SAMS are homogenous areas, our strategy of including two types of areas, affluent and deprived neighborhoods, results in areas that are similar in terms of other characteristics within

\footnotetext{
${ }^{6}$ The segregation index used is an entropy index, which is normalized so that it ranges between zero and unity. A value of zero means complete integration, where all neighborhoods have the same composition as the overall population. A value of unity means complete segregation, where the groups in question are completely separated from each other. The neighborhoods included in the experiment are segregated areas where individuals with low incomes are overrepresented (bad areas) or with high incomes are overrepresented (good areas). See the National Board of Health and Welfare (2006).

${ }^{7}$ To avoid the possibility that employers send regular mail to real residents living at an address, we used real street names but non-existing street numbers. Street numbers were selected close to a real street number for each included street address. We have confirmed that an Internet search on the non-existing street number on a street clearly indicates the location of the street.

${ }^{8}$ A subset of job applications have other arbitrary addresses, i.e., not in a clearly good or bad SAMS. These are excluded from the analysis. We did not randomize good/bad neighborhoods for all job applications, since the neighborhood signals could reduce the external validity of the results for the other hypotheses in the broader project.
} 
neighborhood types but are different between neighborhood types. Thus, not surprisingly, the bad neighborhoods are characterized by low socioeconomic status and high immigrant density. In contrast, good neighborhoods are characterized by high socioeconomic status and low immigrant density. Panel A-D in Figure 1 show average annual income, share of foreign-born residents, employment rate, and share of residents with a university education. ${ }^{9}$ There are clear differences in the averages/shares between bad and good neighborhoods, but not within neighborhood type.

$* * *$ Figure $1 * * *$

Another clear difference between good and bad neighborhoods is their reputation for safety and security. A Swedish police study on criminal networks show that five of six bad neighborhoods are classified as less safe areas, while none of the good neighborhoods are classified as less safe (Rikskriminalpolisen, 2014; see Appendix Figure A1).

A relevant question is whether employers know which residential addresses are located in bad and good neighborhoods. If the signal is not clear, we will not be able to detect a neighborhood signaling effect. The residential address contains three parts - a street name (and number), a postal code, and a municipality name. If employers are unfamiliar with the street name and postal code, they may easily locate them on a map using the Internet. Since we find that employers act on commuting time, they must in the end have some idea of in which area the residential address is located. With this information most employers are also likely to have a perception of whether

\footnotetext{
${ }^{9}$ These statistics are obtained from Statistics Sweden.
} 
the neighborhood is good or bad. ${ }^{10}$ However, given the uncertainty about the signal's strength, one should interpret our estimates of the signal of neighborhood as lower bounds.

We have to control for commuting distance in order to identify the neighborhood signaling effect. For example, if bad neighborhoods are, on average, farther away from jobs and employers avoid hiring job applicants with long commutes, then we cannot separate the neighborhood signaling effect from the confounding effect of commuting time.

We extracted information on commuting time from the Stockholm and Gothenburg public transport websites (www.resplanerare.sl.se and www.vasttrafik.se, respectively) when leaving home at 7 am on a Monday. For each sent job application, we entered the address stated in the job application and the address of the firm to which we applied for a job and then recorded the website's estimate of the commuting time. Of the 2,790 job applications, we were able to retrieve commuting time data for 2,049 job applications. ${ }^{11}$

The average commuting time for good neighborhoods is approximately 50 minutes, while the average commuting time for bad neighborhoods is approximately 45 minutes, a difference of only 5 minutes that favors bad neighborhoods (see panel A in Figure 2). This suggests there is no strong correlation between the type of neighborhood and the commuting time in these two cities of Sweden. ${ }^{12}$ A similar result is reported in Åslund et al. (2010) who find that there is no ethnic difference in the distance to available jobs in these Swedish cities. However, we still control for

\footnotetext{
${ }^{10}$ Some employers may also have used information provided by the name of the municipality. Most employers are likely to be familiar with the municipalities we use, and the characteristics of the SAMS and the municipalities are correlated.

${ }^{11}$ The addresses of the firms were obtained from Statistics Sweden. For 445 job applications, we were not able to calculate the commuting time because the firm's address was missing. For another 296 job applications, commuting time is missing because the firm is located outside the public transport zone.

${ }^{12}$ Most deprived neighborhoods in Stockholm and Gothenburg were built as part of a government program in the 1960 's. They are suburban areas, but have good public transportation to the inner city where most jobs are located (Andersson et al., 2010; Åslund et al., 2010). This may explain why there is no large difference in commuting time between deprived and affluent neighborhoods. This is in contrast to US cities where ethnic minorities usually have longer distances to available jobs (Ihlanfeldt and Sjoquist, 1998) and poor access to public transportation (Kain, 1968). Swedish cities are more similar to other European cities. For example, Gobillon and Selod (2007) show that ethnic minorities from North Africa in Paris have similar access to jobs compared to the native French.
} 
commuting time in the empirical analysis since we are interested in the association between the commuting time itself and the callback rate.

Although Gothenburg is smaller than Stockholm, the average commuting time for Gothenburg (60 minutes) is higher than for Stockholm (42 minutes). This is probably explained by Stockholm's underground metro system, which is likely to be faster than the trams and buses that are the two main options for public transportation in Gothenburg (see panel B and C in Figure $2)^{13}$

$$
* * * \text { Figure } 2 * * *
$$

\subsection{Identities of the applicants}

Since the broader project of which this paper is a part was designed to also investigate gender and ethnic discrimination, it includes typical native Swedish names for both males and females and typical Middle Eastern names for males. Because of statistical power considerations, we limited the number of dimensions of the broader project and therefore did not include females with Middle Eastern names. Hence, in the remainder of this article, typical Middle Eastern names refer to male names. In each of the three groups of applicants, we used names that are among the most common in Sweden. ${ }^{14}$

\footnotetext{
${ }^{13}$ The average commuting time in the experiment is higher than the average among the population. The reason is that the experimental design allows for all combinations of addresses of the fictitious applicants and of firms with a vacancy. This is in contrast to reality where there can be sorting of workers to firms where the commuting time is lower. Survey evidence reveal that the average commuting time for those commuting inside Stockholm and Gothenburg is 29 and 24 minutes, respectively (Rosqvist et al., 2011). Furthermore, $8 \%$ report that they commute to these areas from the outside with average commuting times of one hour. We get almost identical estimates of the neighborhood signaling effect when those with the longest commuting times in the experiment ( $>90$ minutes) are excluded.

${ }^{14}$ The names used are Anna Nilsson, Erik Johansson, Ali Mustafa, Mohammed Ismail, and Hassan Said.
} 


\subsection{Occupations}

In total, thirteen of the most common occupations in the Swedish labor market were included in the field experiment. The occupations include skilled, semiskilled and unskilled occupations. The included occupations were shop sales assistants, construction workers, computer professionals, motor vehicle drivers, business sales assistants, teachers (math/science and language teachers in compulsory school and a general category of secondary school teachers), accountants, nurses, restaurant workers, cleaners and maintenance/repair (see Appendix Table A1).

\subsection{Constructing resumes}

We aimed to construct resumes that represented a typical worker in each occupation. The first step was to construct a resume template for each occupation that only contained general content. This was achieved by using real resumes that were available from a Swedish Employment Service database where job applicants can record their job applications. Specifically, we combined pieces of information from different real job applications into each occupational template and adjusted the level of the qualifications and the stated skills to fit the type of jobs we were going to apply to. In this process, we looked at a large number of real job advertisements to get an idea of what type and level of skills the firms wanted in each occupation. Here we also used our previous experience conducting similar experiments and involved other people that gave feedback on the job applications.

In the next step, random numbers were drawn for each characteristic that could vary in the job application using a statistical software package. These characteristics are type of neighborhood, ethnic background, gender, resume layout, and the order in which the resumes were sent. Half of the resumes have an address in a good neighborhood and half in a bad neighborhood. One third of the job applicants have a typical Swedish male name, Swedish female name, and Middle 
Eastern male name, respectively. There are three resume layouts and three orders in which the applications could be sent (since we sent three applications to each job, see below). One third of each job applications has a particular layout and was sent at a particular position among the three. A computer program written in Visual Basic generated the final job applications by completing the resumes' templates with content depending on the randomized variables and the occupation. In the end, the resume consisted of a personal letter on one page and a detailed CV on another page.

\subsection{Sampling and recording responses}

We collected all employment advertisements that were posted on the Swedish Employment Service webpage (in Stockholm and Gothenburg for the included occupations) from March to November 2007. Three job applications were sent to the same employer. Sending multiple applications meant that the desired number of observations could be obtained with fewer resources. However, there is a trade-off between using the resources efficiently and a higher risk of being detected when sending multiple job applications. Therefore, we decided to not send more than three job applications to the same employer. We created email addresses and registered telephone numbers (with voicemail) to enable employers to contact the fictitious job applicants.

\section{Results for the neighborhood signaling effect}

Panel A in Table 1 shows that 2,790 job applications were sent to employers with advertised positions. ${ }^{15}$ The callback rate is approximately .26 , meaning that around $1 / 4$ of the applications resulted in an invitation to a job interview. Roughly one-half of the job applications $(1,373)$

\footnotetext{
${ }^{15}$ We sent 1,959 and 831 job applications in Stockholm and Gothenburg, respectively.
} 
signaled living in a bad neighborhood, and the callback rate for these job applications is approximately .24. The other half of the job applications $(1,417)$ signaled living in a good neighborhood, and the callback rate for these job applications is approximately .27 .

*** Table $1 * * *$

Panel B in Table 1 presents the callback rates for different commuting times. The majority of job applications $(1,598)$ have commuting times of less than 60 minutes. A total of 352 and 97 job applications have commutes of 61-90 minutes and more than 90 minutes, respectively. The callback rate for the two categories of job applications with commutes of less than 90 minutes are similar (.26 and .28, respectively), while job applications with commutes of more than 90 minutes deviate, with a much lower callback rate of .19.

To analyze the data formally we start by regressing the callback indicator on a dummy variable that equals 1 if the job application has a postal address in a bad neighborhood and 0 otherwise (thus, the reference category is living in a good neighborhood) without controls for commuting time. We use the linear probability model (OLS) for estimation and for precision we control for other randomly assigned characteristics of the job application (work experience, education, personal attributes, unemployment duration, leisure activity, order and the type of the application) and city and occupation. Excluding these characteristics makes little difference for the estimates of the parameters of interest. Overall, we find evidence of a weak negative neighborhood signaling effect in this specification. The first column in Table 2 shows a point estimate of $-.027(\mathrm{p}<.1) .{ }^{16}$ The interpretation is that the callback rate is 2.7 percentage points (or

\footnotetext{
${ }^{16}$ This comparison of group means is slightly underpowered (power is about $60 \%$ ), i.e. a slightly larger sample size would be desired to detect effects of this magnitude.
} 
14 percent) lower for job applicants who signal living in a bad neighborhood as opposed to a good one.

$* * *$ Table $2 * * *$

The neighborhood signaling effect may differ by ethnicity. To investigate this possibility, we estimate a specification that allows for different neighborhood signaling effects for job applicants with typical native Swedish and Middle Eastern names. Row 2 and 3 of column 2 report the results of this regression model. Interestingly, we only find evidence of a negative neighborhood signaling effect for job applicants with Middle Eastern names. While the neighborhood signaling effect is close to zero (-.003) and statistically non-significant for job applicants with typical Swedish names, there is a substantial negative effect (-.057) for job applicants with Middle Eastern names $(\mathrm{p}<.05) .{ }^{17}$ This implies that job applicants with typical Middle Eastern names have a 42 percent lower probability of receiving a callback for a job interview if their resume signals that they live in a bad neighborhood as opposed to a good one. ${ }^{18}$

Next, we repeat the regressions in column 1 and 2, but with controls for commuting time using dummy indicators for commuting times of 61-90 and more than 90 minutes, where 0-60 minutes is the omitted category; see column 3 and 4 in Table 2. We find no evidence that commuting time is an important control variable; the estimates of the neighborhood signaling effect are essentially unchanged. This holds as well if we include commuting time as a continuous variable or using percentile dummies (see Table A2).

\footnotetext{
${ }^{17}$ For applicants with typical Swedish names, the $95 \%$ confidence interval includes point estimates in the interval from -.043 to .037 . The ethnic difference has a power of about $80 \%$ given the sample size of the ethnic minority and using a one-sided test.

${ }^{18}$ If we exclude applicants with typical Swedish female names, the estimated coefficients in columns 1 and 2 are very similar in terms of magnitude (only marginally stronger) and statistical significance.
} 
However, we are also interested in whether commuting time in itself is associated with callbacks for job interviews. There is no significant difference in callback rates between commuting times of 0-60 and 61-90, but job applicants with commutes longer than 90 minutes have substantially lower callback rates $(\mathrm{p}<.01$; column 3 and 4 in Table 2$)$. The interpretation of the latter coefficient is that the callback rate is approximately 12 percentage points lower for job applicants that have to commute more than 90 minutes compared to those with a commuting time less than 60 minutes. $^{19}$

Finally, we find no statistical evidence of a difference in the callback rates of job applicants with native Swedish male and female names when living in either good or bad neighborhoods; see Column 3 in Table A3. ${ }^{20}$ However, for commuting time, Column 4 in Table A3 reveals that especially female applicants with commutes longer than 90 minutes appear to have substantially lower callback rates. The point estimate is significantly different from zero $(\mathrm{p}<.01)$, but not statistically different from the other two applicants.

\section{Interpretations}

In light of statistical discrimination theories, the callback rate of minority job applicants living in worse neighborhoods could be lower if recruiters believe that there are important skills of the job applicants that are unobserved to the employers. In these models, signaling a good neighborhood

\footnotetext{
${ }^{19}$ Note that since this is a non-experimental variable and employers' perceptions about commuting time may deviate from our measure, the estimate should be interpreted with some caution.

${ }^{20}$ This analysis of a gender difference has low power since the sample size makes us reliably detect only effects that are larger in magnitude. See also footnote 16 and 17. We have also examined heterogeneity w.r.t. city and occupational skill level. Due to power considerations we only mention the point estimates briefly. For applicants with native Swedish sounding names the neighborhood signaling effects are similar and close to zero for both cities. For job applicants with typical Middle Eastern names, the neighborhood signaling effects are also very similar, -.057 for Stockholm and -.058 for Gothenburg. In terms of the skill level of the occupations, job applicants with native Swedish sounding names have neighborhood signaling effects that are similar, and close to zero, in both cases. For job applicants with a Middle Eastern (male) name the effect appears stronger in high skilled occupations (-.11) than in low skilled occupations (-.03). The latter two point estimates are statistically different at the ten percent level.
} 
could then be more informative about the productivity of job applicants with typical Middle Eastern (male) names. In other words, the strength of the neighborhood signal is stronger for the ethnic minority. As a result, the callback rate increases relatively more for job applicants with typical Middle Eastern names compared to those with typical Swedish names when changing from a bad neighborhood to a good one. The underlying mechanism could be that employers believe that individual productivity is lower among minority job candidates living in bad neighborhoods compared to good neighborhoods, but this do not apply for majority job applicants. A possibility is that employers infer information from the type of neighborhood about soft skills, such as host-county specific social capital and communication skills for the ethnic minority. An alternative is that the perceptions emerge from the negative publicity in the news media about these areas, which appears to focus on the people with a foreign background, and not the native Swedes, who live there. Yet another possibility is that employers only gather information about residential location for minority job applicants, because this is costly and for majority applicants the information is not likely to influence the decision whether to give a callback or not.

However, it is also possible to imagine a modified model of preference-based discrimination (Becker, 1957). In such a model, the ethnic difference in the neighborhood signaling effect could be due to preference-based discrimination, with such preferences varying by neighborhood type. For example, those who have grown up in a good neighborhood may, e.g., be viewed more as native Swedes. In general, it is very difficult to distinguish among theories of preference and statistical discrimination in field experiments (Carlsson and Rooth, 2012).

A fascinating result is how much ethnic discrimination changes by moving to a neighborhood with a better reputation. The point estimates in Table 2 reveal ethnic callback gaps of approximately 15 and 9.4 percentage points in bad and good neighborhoods, respectively (a 
statistically significant difference, $\mathrm{p}<.01)$. This implies that ethnic discrimination is reduced by almost 40 percent if a job applicant with a Middle Eastern name moves from a bad neighborhood to a good one.

We also find that employers seem to statistically discriminate against job applicants with long commutes. Potential reasons for this include that employers expect workers with longer commuting times to be less flexible in terms of working hours, be less able to work particular hours, put less effort into work because of tiresome commuting and be more likely to quit if they find a job closer to their neighborhood. ${ }^{21}$ We find that this effect appears to be strongest for female applicants, and one interpretation is that these mechanisms are most important for females who take most responsibility for family and children. Of course, we cannot rule out other mechanisms related to the employers' reactions to job seekers with long commuting times.

\section{Conclusion}

A common pattern in many metropolitan cities is the existence of neighborhoods where individuals who have low incomes and high levels of unemployment are concentrated. An important question is whether living in such deprived neighborhoods causes poor individual labor market outcomes. To investigate this question, we conducted a field experiment in the Swedish labor market in which 2,790 job applications were sent to employers with job vacancies. In our experiment, we randomly assigned residential addresses to the job applications and control for commuting distance, which leaves us with the neighborhood signaling effect.

We find no evidence of a neighborhood signaling effect for typical native Swedish names. In contrast, for typical Middle Eastern names, we find a significant neighborhood signaling effect.

\footnotetext{
${ }^{21}$ A long commuting time could also send a signal about low productivity more generally if workers who do not find a job easily search in a wider geographical area.
} 
Job applicants with typical Middle Eastern names who signal living in a bad neighborhood rather than a good one receive 42 percent fewer callbacks for job interviews. Moreover, adding a control for commuting time does not change the results, meaning that this do not appear to be a confounding factor of the neighborhood signaling effect. However, we find that a long commute is itself negatively associated with callback rates. Apparently, employers consider information about residential addresses important for their employment decisions.

While our experimental approach is an effective way of identifying unequal treatment in hiring, it still has some weaknesses. First, our analysis relies on that the employers'́ perceptions about neighborhood types and commuting time, at least partly, reflect the reality. We provide indirect evidence of this, but there remains uncertainty about how accurate the perceptions are. Second, our approach measures unequal treatment only at the initial stage of the hiring process, but unequal treatment may also exist in promotions and wage setting. Third, our findings apply only to job applicants that use a formal search method to find a job, whereas many job applicants use informal search methods or choose to become self-employed. 


\section{References}

Aigner, D.J. and Cain, G.G. (1977), "Statistical Theories of Discrimination in Labor Markets", ILR Review, Vol. 30 No. 2, pp. 175-187.

Aldén, L. and Hammarstedt, M. (2016), "Boende med konsekvens: en ESO-rapport om etnisk bostadssegregation och arbetsmarknad", ESO report no. 2016:1, Finansdepartementet, Stockholm.

Andersson, R., Bråmå, Å. and Holmqvist, E. (2010), “Counteracting Segregation: Swedish policies and Experience”, Housing Studies, Vol. 25 No. 2, pp. 237-256.

Andersson, R. and Bråmå, Å., (2004), "Selective Migration in Swedish Deprived Neighborhoods: Can Area-based Urban Policies Counteract Segregation Process?”, Housing Studies, Vol. 19 No. 4, pp. 517-539.

Arrow, K.J. (1973), "The Theory of Discrimination", in Ashenfelter, A. and Rees, A. (Eds.), Discrimination in labor markets, Princeton University Press, Princeton, NJ, pp. 3-33.

Åslund, O., Östh, J. and Zenou, Y. (2010), "How important is access to jobs? Old questionimproved answer", Journal of Economic Geography, Vol. 10 No. 3, pp. 389-422.

Atkinson R. and Kintrea K. (2001), “ Disentangling Area Effects: Evidence from Deprived and Non-Deprived Neighborhoods", Urban Studies, Vol. 38 No. 11, pp. 2277-2298.

Baert, S., Cockx, B., Gheule, N. and Vandamme, C. (2015), "Is There Less Discrimination in Occupations Where Recruitment Is Difficult?’, ILR Review, Vol. 68 No. 3, pp. 467-50.

Baert, S., De Pauw, A.S. and Deschacht, N. (2016a), "Do employer preferences contribute to sticky floors?", ILR Review, Vol. 69 No. 3, pp. 714-736.

Baert, S., Norga, J., Thuy, Y. and Van Hecke, M. (2016b), "Getting grey hairs in the labour market. An alternative experiment on age discrimination”, Journal of Economic Psychology, Vol. 57, pp. 86-101. 
Baert, S. (2017), "Hiring Discrimination: An Overview of (Almost) All Correspondence Experiments Since 2005”, IZA Discussion Paper No. 61, Bonn, April.

Bartoš, V., Bauer, M., Chytilová, J. and Matějka, F. (2016), “Attention Discrimination: Theory and Field Experiments with Monitoring Information Acquisition", American Economic Review, Vol. 106 No. 6, pp. 1437-75.

Becker, G.S. (1957), The economics of discrimination, University of Chicago Press, Chicago.

Bertrand, M. and Mullainathan, S. (2004), “Are Emily and Greg More Employable Than Lakisha and Jamal? Field Experiment on Labor Discrimination", The American Economic Review, Vol. 94 No. 4, pp. 991-1014.

Borjas, G.J., (1995), "Ethnicity, Neighborhoods, and Human-Capital Externalities", The American economic Review, Vol. 85 No. 3, pp. 365-39.

Carlsson, M. and Eriksson, S. (2017), "The Effect of Age and Gender on Labor Demand Evidence from a Field Experiment”, working paper No. 2017:4, Center for Discrimination and Integration Studies, Linnaeus University, Växjö, 26 June.

Carlsson, M. Reshid, A.A. and Rooth, D. (2015), "Explaining the gender wage gap among recent college graduates - Pre-labor market factor or employer discrimination", working paper No. 2015:7, Center for Labour Market and Discrimination Studies, Linnaeus University, Växjo, 18 November.

Carlsson, M. and Rooth, D. (2012), "Revealing Taste-Based Discrimination in Hiring: A Correspondence Testing Experiment with Geographic Variation", Applied Economics Letters, Vol. 19 No. 18, pp. 1861-1864.

Carlsson, M. (2011), "Does Hiring Discrimination Cause Gender Segregation in the Swedish Labor market?", Feminist Economics, Vol. 17 No. 3, pp. 71-102. 
Carlsson, M. (2010), "Experimental Evidence of Discrimination in the Hiring of First-and Second-generation Immigrants”, Labour, Vol. 24 No. 3, pp. 263-278.

Carlsson, M. and Rooth, D. (2007), "Evidence of ethnic discrimination in the Swedish labor market using experimental data", Labour Economics, Vol. 14, pp. 716-729.

Chetty, R., Hendren, N. and Katz, L.F. (2016), "The Effect of Exposure to Better Neighborhoods on Children: New Evidence from the Moving to Opportunity Experiment", American Economic Review, Vol. 106 No. 4, pp. 855-902.

Durlauf, S.N. (2004), "Neighborhood Effects", in Henderson, J.V. and Thisse, J.F. (Eds.) Handbook of regional and urban economics (Volume 4), Cities and Geography, Elsevier, Amsterdam, pp. 2173-2242.

Eriksson, S. and Rooth, D. (2014), "Do Employers Use Unemployment as a Sorting Criterion When Hiring? Evidence from a Field Experiment", American Economic Review, Vol. 104 No. 3, pp. 1014-1039.

Galster, G., Andersson, R. and Musterd, S., (2015), “Are Males' Incomes Influenced by the Income Mix of Their Male Neighbours? Explorations into Nonlinear and Threshold Effects in Stockholm”, Housing Studies, Vol. 30 No. 2, pp. 315-343.

Gobillon, L., Selod, H. and Zenou, Y. (2007), "The mechanisms of spatial mismatch", Urban Studies, Vol. 44 No. 12, pp. 2401-2427.

Gobillon, L. and Selod, H. (2007), "The Effect of Segregation and Spatial Mismatch on Unemployment: Evidence from France”, CEPR Discussion Paper, no. DP6198, 20 May.

Grönqvist, H., Niknami, S. and Robling, P., (2015), "Child Exposure to Segregation and Longrun Criminal Involvement - Evidence from the "While of Sweden" Strategy", working paper No 1/2015, Swedish Institute for Social Research, Stockholm University, Stockholm, 10 March. 
Ihlanfeldt, K.R. and Sjoquist, D.L. (1998), "The spatial mismatch hypothesis: A review of recent studies and their implications for welfare reform", Housing Policy Debate, Vol. 9 No. 4, pp. 849-892.

Kain, J. (1968), "Housing segregation, negro employment, and metropolitan decentralization", Quarterly Journal of Economics, Vol. 82 No. 2, pp. 175-197.

Katz, L., Kling, J. and Liebman, J. (2001), "Moving to opportunity in Boston: early results of a randomized mobility experiment", Quarterly Journal of Economics, Vol. 116 No. 2, pp. 607654.

Kroft, K., Lange, F. and Notowidigdo, M.J. (2013), "Duration Dependence and Labor Market Conditions: Evidence from a Field Experiment", Quarterly Journal of Economics, Vol. 128 No. 3, pp. 1123-67.

Lee, H.A. and Khalid, M.A. (2016), "Discrimination of high degrees: race and graduate hiring in Malaysia”, Journal of the Asia Pacific Economy, Vol. 21 No. 1, pp. 53-76.

Lahey, J.N. (2008), "Age, women, and hiring an experimental study", Journal of Human resources, Vol. 43 No. 1, pp. 30-56.

Midtbøen, A.H. (2016), "Discrimination of the second generation: Evidence from a field experiment in Norway", Journal of International Migration and Integration, Vol. 17 No. 1, pp. 253-272.

National Board of Health and Welfare. (2006), Social rapport I: Boendesegregation, Socialstyrelsen. Stockholm.

Neumark, D., Bank, R.J. and Van Nort, K.D. (1996), "Sex discrimination in restaurant hiring: An audit study", The Quarterly Journal of Economics, Vol. 111 No. 3, pp. 915-941.

Neumark, D. (2016), "Experimental research on labor market discrimination", No. w22022, National Bureau of Economic Research, Cambridge MA, February. 
Phelps, E.S. (1972), “The Statistical Theory of Racism and Sexism”, The American Economic Review, Vol. 62 No. 4, pp. 659-661

Phillips, D.C. (2016), Do Low-Wage Employers Discriminate Against Applicants with Long Commutes? Evidence from a Correspondence Experiment", Unpublished Manuscript, available at: https://sites.google.com/site/davidcphillipseconomics/research.

Riach, P.A. (2015), “A field experiment investigating age discrimination in four European labour markets. International Review of Applied Economics”, Vol. 29 No. 5, pp. 608-619.

Riach, P.A. and Rich, J. (2002), "Field Experiments of Discrimination in the Market Place", Economic Journal, Vol. 112 No. 483, pp. F480-F518.

Rich, J. (2014), "What Do field Experiments of Discrimination in Markets Tell Us? A Meta Analysis of Studies Conducted since 2000”, IZA Discussion Paper No. 8584, The Institute for the Study of Labor (IZA), Bonn, October.

Rikskriminalpolisen (2014), "En nationell översikt av kriminella nätverk med stor påverkan i lokalsamhället. Underrättelsektionen”, Stockholm, Rikskriminalpolisen, pp. 1-29.

Rosqvist, L.S., Adel, E., Indebetou, L., Hanander, M., Dickinson, J. and Ljungberg, C. (2011), "Arbetspendlingen i Sveriges storstadsområden - nuläge, brister och förtjänster”, Trivector Report 2011:37 version 1.1, Trivector Traffic AB, Stockholm, pp.1-76.

Tammaru, T., Van Ham, M., Marcinczak, S. and Musterd, S. (2015), Socio-Economic segregation in European Capital Cities: East Meets West, Rouledge, London.

Tunstall, R., Green, A., Lupton, R., Watmough, S. and Bates, K. (2014), "Does poor neighbourhood reputation create a neighbourhood effect on employment? The results of a field experiment in the UK", Urban Studies, Vol. 51 No. 4, pp. 763-78. 
Wacquant, L. (1993), "Urban outcasts: stigma and division in the black American ghetto and the French urban periphery", International Journal of Urban and Regional Research, Vol. 17 No. 3, pp. 366-383.

Weichselbaumer, D. (2017), "Discrimination Against Migrant Job Applicants in Austria: An Experimental Study”, German Econ Rev, Vol. 18 No. 2, pp. 237-265.

Wilson, W.J. (1987), The Truly Disadvantaged, University of Chicago Press, Chicago, IL. 


\section{Tables}

Table 1. Descriptive results of the field experiment.

\begin{tabular}{lcc}
\hline \hline & Callback rate & $\begin{array}{c}\text { Number of job } \\
\text { applications }\end{array}$ \\
\hline A) Bad and good neighborhoods & & \\
& & \\
All Applications & .26 & 2,790 \\
Bad Neighborhood & .24 & 1,373 \\
Good Neighborhood & .27 & 1,417 \\
B) Commuting time & & \\
All Applications & & \\
$<60$ minutes & .26 & 2,790 \\
$60-90$ minutes & .26 & 1,598 \\
$>90$ minutes & .28 & 352 \\
Commuting time missing & .19 & 97 \\
& .26 & 743 \\
\hline \hline
\end{tabular}

Table 2. The neighborhood signaling effect and commuting time.

\begin{tabular}{|c|c|c|c|c|}
\hline & $(1)$ & $(2)$ & (3) & (4) \\
\hline Bad neighborhood & $\begin{array}{l}-.027^{*} \\
(.016)\end{array}$ & & $\begin{array}{l}-.028^{*} \\
(.016)\end{array}$ & \\
\hline $\mathrm{x}$ native Swedish name & & $\begin{array}{l}-.003 \\
(.021)\end{array}$ & & $\begin{array}{l}-.004 \\
(.021)\end{array}$ \\
\hline x Middle Eastern name & & $\begin{array}{l}-.057^{* *} \\
(.024)\end{array}$ & & $\begin{array}{l}-.059^{* *} \\
(.024)\end{array}$ \\
\hline Middle Eastern name ( good neighborhood) & & $\begin{array}{c}-.094^{* * *} \\
(.023)\end{array}$ & & $\begin{array}{c}-.095^{* * *} \\
(.023)\end{array}$ \\
\hline $61-90$ minutes & & & $\begin{array}{l}-.005 \\
(.027)\end{array}$ & $\begin{array}{l}-.005 \\
(.027)\end{array}$ \\
\hline$>90$ minutes & & & $\begin{array}{l}-.118^{* * *} \\
(.045)\end{array}$ & $\begin{array}{l}-.124^{* * *} \\
(.045)\end{array}$ \\
\hline Constant & $\begin{array}{l}.192^{* *} \\
(.078)\end{array}$ & $\begin{array}{l}.231^{* * *} \\
(.078)\end{array}$ & $\begin{array}{l}.191^{* *} \\
(.078)\end{array}$ & $\begin{array}{l}.231^{* * *} \\
(.078)\end{array}$ \\
\hline $\begin{array}{l}\text { Number of job applications } \\
\text { p-value (H0: equal neighborhood coeff. for Swedish and Middle Eastern name) }\end{array}$ & 2,790 & $\begin{array}{c}2,790 \\
.091\end{array}$ & 2,790 & $\begin{array}{l}2,790 \\
.087\end{array}$ \\
\hline
\end{tabular}

Notes: The dependent variable is the callback indicator. The reference category is good neighborhood in column 1, Swedish name and good neighborhood in Column 2. Column 3 and 4 add controls for commuting time. The reference category for commuting time is less than or equal to 60 minutes. In the specifications of columns 3 and 4 , we also add a dummy for the missing observations on commuting time (which is equal to 1 if commuting time is missing and zero otherwise). All model specifications are linear probability models and controls for individual attributes on work experience, education, personal attributes, unemployment spell, leisure activity, city, occupation, order and format of the application. The standard errors are clustered at the job level. *,** and *** denote 10, 5 and 1 percent significance level. 


\section{Figures}

Figure 1: Socio-economic characteristics of neighborhoods.

Figure A: Average Annual Income

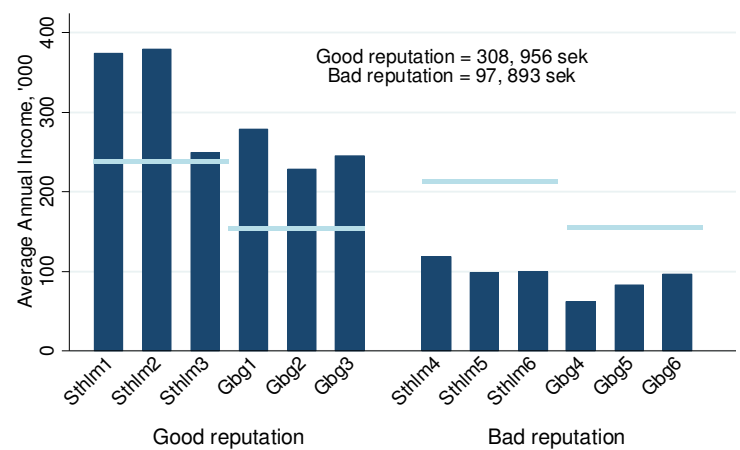

Figure C: Employment Rate

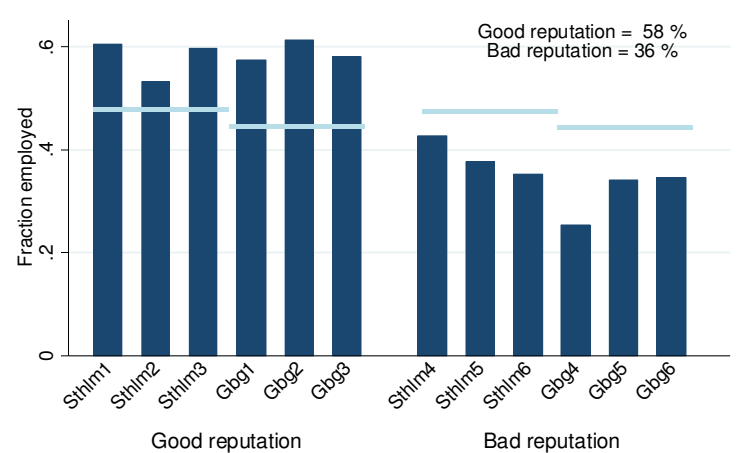

Figure B: Share with Foreign background

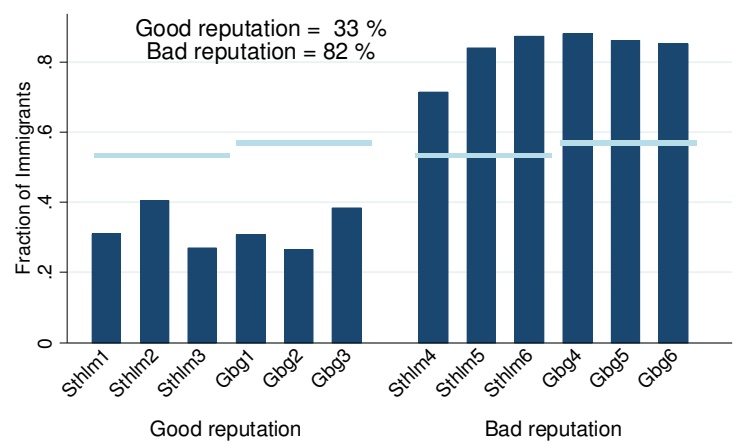

Figure D: Share with University Education

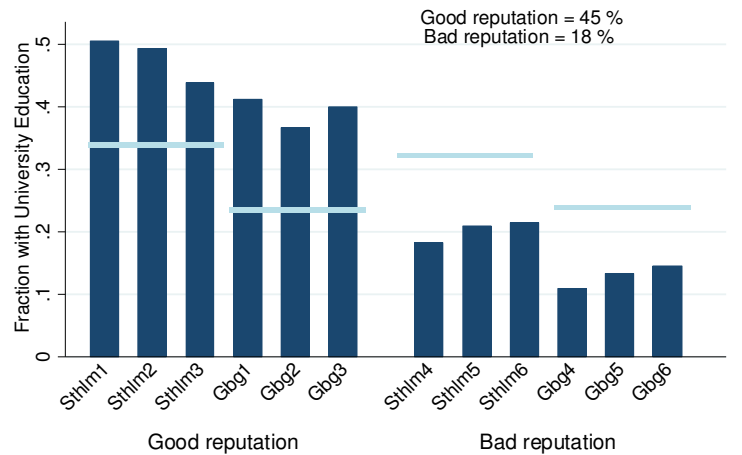

Notes: Data is from Statistics Sweden for 2007. Neighborhoods are defined at the Small Area Market Statistics (SAMS) level. The labels on the $\mathrm{x}$-axis represent the 12 neighborhood addresses used in the experiment. Sthlm1-3 and Gbg1-3 represent the three good neighborhoods in Stockholm and Gothenburg, respectively. Sthlm4-6 and Gbg4-6 represents the three bad neighborhoods in Stockholm and Gothenburg, respectively. For each variable in Figure A-D the horizontal line shows the mean value across all neighborhood areas in Stockholm and Gothenburg, respectively. 
Figure 2: The distribution of commuting time.

Figure A: Commuting Time in Minuts
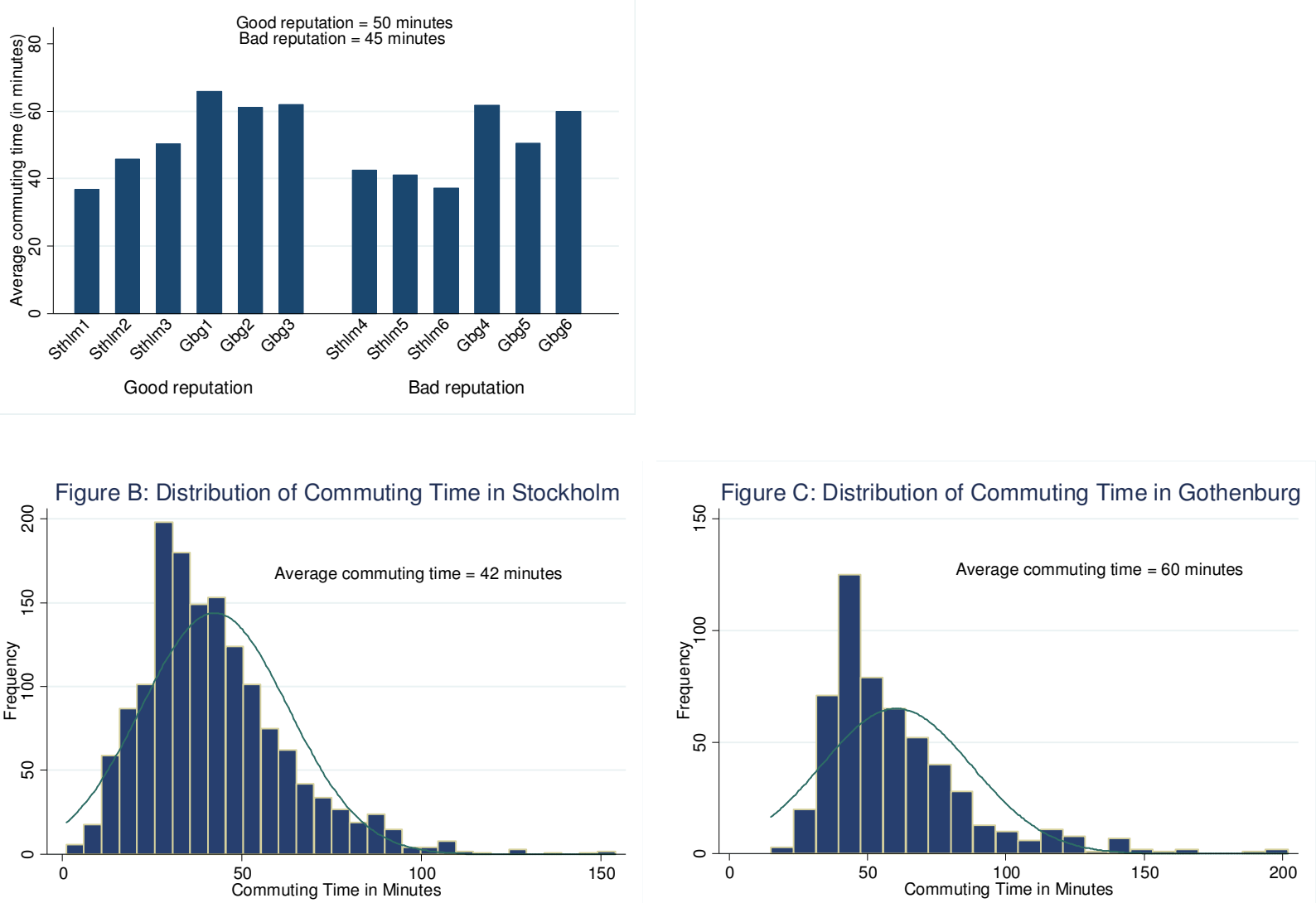

Notes: For Figure 2:A, see the notes below Figure 1. 


\section{Appendix A}

Table A1: Descriptive Statistics of the occupations.

Occupations Number of job applications Fraction job applications

High skill jobs

Computer professionals

352

.13

Accountants and auditors

227

.08

Compulsory school teachers (math/natural Science)

102

.04

Compulsory school teachers (Swedish/social science)

107

.04

Secondary school teachers

121

.04

Registered nurses

140

.05

Low and medium skill jobs

Cleaners

139

.05

Installation, maintenance, and repair occupations

101

.04

Shop sales assistant

372

.13

Construction workers

153

.05

Motor vehicle driver

211

.08

Business sales assistant

574

.21

Restaurant workers

191

.07 
Table A2. The neighborhood signaling effect, commuting time cont. and using percentiles.

\begin{tabular}{|c|c|c|c|c|}
\hline & $(1)$ & $(2)$ & (3) & (4) \\
\hline Bad neighborhood & $\begin{array}{l}-.031^{*} \\
(.016)\end{array}$ & $\begin{array}{l}-.030^{*} \\
(.016)\end{array}$ & & \\
\hline $\mathrm{x}$ native Swedish name & & & $\begin{array}{l}-.007 \\
(.021)\end{array}$ & $\begin{array}{l}-.006 \\
(.021)\end{array}$ \\
\hline x Middle Eastern name & & & $\begin{array}{l}-.063^{* *} \\
(.024)\end{array}$ & $\begin{array}{l}-.060^{* *} \\
(.024)\end{array}$ \\
\hline Middle Eastern name ( good neighborhood) & & & $\begin{array}{c}-.094^{* * *} \\
(.023)\end{array}$ & $\begin{array}{c}-.094^{* * *} \\
(.023)\end{array}$ \\
\hline Commuting time (minutes) & $\begin{array}{r}-.001^{* * *} \\
(.0004)\end{array}$ & & $\begin{array}{r}-.001^{* * *} \\
(.0004)\end{array}$ & \\
\hline Commuting time & & & & \\
\hline 25 - 75 percentile & & $\begin{array}{l}-.024 \\
(.024)\end{array}$ & & $\begin{array}{l}-.017 \\
(.023)\end{array}$ \\
\hline 75 - 90 percentile & & $\begin{array}{l}-0.024 \\
(.028)\end{array}$ & & $\begin{array}{l}-.021 \\
(.027)\end{array}$ \\
\hline $90+$ percentile & & $\begin{array}{l}-.086^{* *} \\
(.040)\end{array}$ & & $\begin{array}{l}-.088^{* *} \\
(.039)\end{array}$ \\
\hline Constant & $\begin{array}{l}.249^{* * *} \\
(.080)\end{array}$ & $\begin{array}{l}.239^{* * *} \\
(.081)\end{array}$ & $\begin{array}{l}.288^{* * *} \\
(.080)\end{array}$ & $\begin{array}{l}.269^{* * *} \\
(.081)\end{array}$ \\
\hline $\begin{array}{l}\text { Number of job applications } \\
\text { p-value (H0: equal neighborhood coeff. for Swedish and Middle Eastern name) }\end{array}$ & 2,790 & 2,790 & $\begin{array}{c}2,790 \\
.084\end{array}$ & $\begin{array}{c}2,790 \\
.088\end{array}$ \\
\hline
\end{tabular}

Notes: In the specifications of columns 1 and 3, we have imputed the mean commuting time and also added a dummy indicator for when commuting time is missing. See also the notes below Table 2 . 
Table A3. Neighborhood signaling effect and gender.

\begin{tabular}{|c|c|c|c|c|}
\hline & 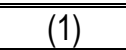 & $(2)$ & (3) & $(4)$ \\
\hline Bad neighborhood & $\begin{array}{l}-.028^{*} \\
(.016)\end{array}$ & & & \\
\hline $\mathrm{x}$ native Swedish name & & $\begin{array}{c}-.003 \\
(.021)\end{array}$ & & \\
\hline $\mathrm{x}$ native Swedish male name & & & $\begin{array}{l}-.014 \\
(.029)\end{array}$ & $\begin{array}{l}-.012 \\
{[.029]}\end{array}$ \\
\hline $\mathrm{x}$ native Swedish female name & & & $\begin{array}{l}.003 \\
(.030)\end{array}$ & $\begin{array}{c}.003 \\
{[.030]}\end{array}$ \\
\hline x Middle Eastern name & & $\begin{array}{c}-.057^{* *} \\
(.024)\end{array}$ & $\begin{array}{c}-.059^{* *} \\
(.024)\end{array}$ & $\begin{array}{c}-.059^{* *} \\
{[.024]}\end{array}$ \\
\hline Middle Eastern name (good neighborhood) & & $\begin{array}{c}-.094^{* * *} \\
(.023)\end{array}$ & $\begin{array}{c}-.080^{\star \star \star} \\
(.026)\end{array}$ & $\begin{array}{c}-.073^{* * *} \\
{[.027]}\end{array}$ \\
\hline native Swedish female name (good neighborhood) & & & $\begin{array}{c}.031 \\
(.028)\end{array}$ & $\begin{array}{c}.038 \\
{[.030]}\end{array}$ \\
\hline $61-90$ minutes & $\begin{array}{l}-.005 \\
(.027)\end{array}$ & $\begin{array}{l}-.005 \\
(.027)\end{array}$ & $\begin{array}{l}-.006 \\
(.027)\end{array}$ & \\
\hline $\mathrm{x}$ native Swedish male name & & & & $\begin{array}{c}.016 \\
(.047)\end{array}$ \\
\hline $\mathrm{x}$ native Swedish female name & & & & $\begin{array}{l}-.007 \\
(.046)\end{array}$ \\
\hline $\mathrm{x}$ Middle Eastern male name & & & & $\begin{array}{l}-.040 \\
(.057)\end{array}$ \\
\hline$>90$ minutes & $\begin{array}{c}-.118^{\star * *} \\
(.045)\end{array}$ & $\begin{array}{c}-.124^{\star * *} \\
(.045)\end{array}$ & $\begin{array}{c}-.126^{* * *} \\
(0.045)\end{array}$ & \\
\hline $\mathrm{x}$ native Swedish male name & & & & $\begin{array}{l}-.072 \\
(.079)\end{array}$ \\
\hline $\mathrm{x}$ native Swedish female name & & & & $\begin{array}{c}-.185^{\star \star \star} \\
(.066)\end{array}$ \\
\hline $\mathrm{x}$ Middle Eastern male name & & & & $\begin{array}{c}-.036 \\
(.099)\end{array}$ \\
\hline Constant & $\begin{array}{l}.191^{* *} \\
(.078)\end{array}$ & $\begin{array}{l}.231^{* * *} \\
(.078)\end{array}$ & $\begin{array}{c}.227 \\
(.080)\end{array}$ & $\begin{array}{l}.223^{\star * \star} \\
(.080)\end{array}$ \\
\hline Number of job applications & 2,790 & 2,790 & 2,790 & 2,790 \\
\hline
\end{tabular}


Figure A1. Neighborhoods and criminal networks in Stockholm (left) and Gothenburg (right).
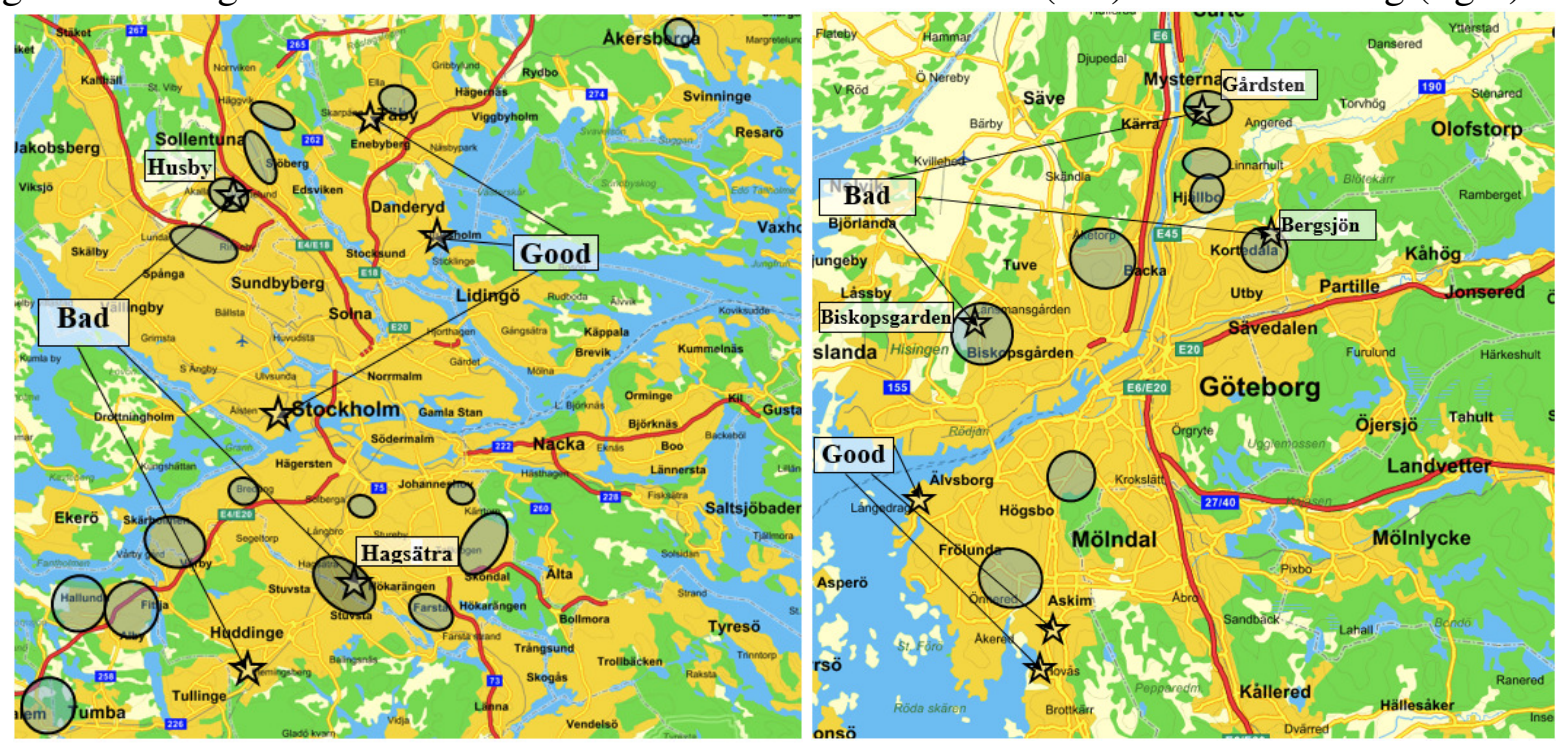

Notes: The circles show the neighborhoods identified as areas with local criminal networks (Rikskriminalpolisen, 2014). The stars show the neighborhoods in the experiment; five out of six of the bad neighborhoods have local criminal networks. None of the good neighborhood has local criminal networks. 